\title{
Pemberdayaan Ekonomi Perempuan Melalui Pengolahan Tanaman Obat Keluarga (TOGA) Menjadi Produk Minuman
}

\author{
Esy Nur Aisyah ${ }^{1^{*}}$ \\ ${ }^{1}$ UIN Maulana Malik Ibrahim Malang \\ Email: esynuraisyah@yahoo.com ${ }^{1}$ \\ *Corresponding author: esynuraisyah@yahoo.com ${ }^{1}$
}

\begin{abstract}
Abstrak
Pemanfaatan Tanaman Obat Keluarga (TOGA) dapat menjadi program pemberdayaan ekonomi bagi perempuan, dalam rangka meningkatkan kesejahteraan keluarga. Program ini telah dimasyarakatkan oleh Lembaga Swadaya Masyarakat melalui program PKK (Pembinaan Kesejahteraan Keluarga). Tujuan dari pengabdian ini adalah meningkatkan ekonomi perempuan di Desa Pandanrejo Kecamatan Wagir Kabupaten Malang melalui pengolahan TOGA menjadi produk minuman. Metode yang digunakan adalah ceramah dan praktik atau demonstrasi. Tanaman yang digunakan bahan minuman dalam pengolahan ini adalah jahe, sereh, kapulaga, jeruk nipis, kayu manis dan daun salam. Dalam pelaksanaannya, cara pengolahan dan khasiat tanaman TOGA menjadi minuman yang menyehatkan terlaksana dengan baik. Disamping itu, peserta mendapatkan pelatihan memasarkan produk minuman tersebut secara online.
\end{abstract}

Kata Kunci: Minuman, Pemberdayaan Ekonomi, Perempuan, Tanaman Obat Keluarga (TOGA)

\begin{abstract}
Utilization of Family Medicinal Plants (TOGA) can be an economic empowerment program for women to improve family welfare. This program has been promoted by non-governmental organization through the Family Welfare Development (PKK). This study aims to improve the economy of women in Pandanrejo village, Wagir district, Malang regency through the processing of Family Medicinal Plants (TOGA) to be beverage products. The method used is lecture and practice (demonstration). The plants used in this beverage are ginger, lemongrass, cardamom, lime, cinnamon, and bay leaf. In its implementation, the way of processing and the efficacy of Family Medicinal Plants (TOGA) into healthy beverage products is well implemented. Besides, participants get online marketing training.
\end{abstract}

Keywords: Economic Empowerment, Women, Beverage Products, Family Medicinal Plants (TOGA) 


\section{PENDAHULUAN}

TOGA adalah tanaman rumahan yang memiliki khasiat pengobatan. Terdapat berbagai manfaat dari TOGA (Nurdiwaty, 2017), yaitu 1) tanaman sayuran seperti timun pepaya, dan bayam dapat menambah gizi keluarga; 2) tanaman rempah-rempah yaitu sereh, jahe, kencur kunyit, dan daun salam dapat menjadi bumbu masakan; 3) tanaman bunga seperti bunga matahari, melati, mawar, tapak dara, kembang sepatu, dan kumis kucing bermanfaat untuk menambah keindahan.

Masyarakat Indonesia mengaggap TOGA adalah obat tradisional dan menjadi warisan budaya bangsa. Karo-Karo (2010) menjelaskan bahwa secara praktik, tanaman tradisional memiliki tiga keuntungan, yaitu 1) Mampu mengobati segala penyakit 2) efek samping yang lebih rendah; 3) mudahnya untuk memperoleh dan meramu tanaman tersebut tanpa bantuan dari tenaga medis. Dengan demikian tanaman obat ini bisa menjadi solusi atas mahalnya obat-obatan di pasaran dengan cara back to nature (Nurjanah et al., 2019).

Budidaya dan pengolahan Tanaman Obat Keluarga (TOGA) adalah bagian dari program peningkatan kesejahteraan keluarga yang mampu dilakukan oleh perempuan. Pemerintah telah menggalakkan TOGA dalam rangka melestarikan sumber daya alam yang yang berasal dari tumbuhan. Program ini telah dimasyarakatkan oleh Lembaga Swadaya Masyarakat melalui program PKK (Pembinaan Kesejahteraan Keluarga). Tetapi sampai saat ini, program TOGA ini tampaknya masih belum berhasil sehingga perlu ditingkatkan pemasyarakatannya.

Program PKK di Desa Pandanrejo rutin dilaksanakan tiap Bulan. berdasarkan hasil survey sebanyak $80 \%$ di kegiatan PKK belum pernah mendapatkan penyuluhan atau pelatihan tentang pengolahan tanaman TOGA. Sehingga, perlu adanya untuk diadakan pelatihan atau penyuluhan tentang pengolahan TOGA. Selain itu, berdasarkan hasil analisis situasi, 70 \% Desa Pandanrejo adalah penghasil tanaman sereh. Dimana tanaman sereh ini memiliki manfaat untuk berbagai penyakit, yaitu diare, batuk, obat sakit kepala, penurun panas, nyeri lambung, penghangat badan, dan pengusir nyamuk (G et al., 2013).

Program pengabdian ini difokuskan pada pemberdayaan ekonomi perempuan di Desa Pandanrejo dengan memberikan pelatihan kepada anggota PKK tentang pengolahan tanaman toga menjadi produk minuman serta memasarkan secara online.

\section{METODE PENELITIAN}

\section{Metode Kegiatan}

Metode pengabdian yaitu Active and Participatory Learning (Nursyamsu, 2018). Metode ini meliputi kegiatan ceramah mengenai khasiat dari TOGA, proses pengolahan TOGA, dan cara memasarkan hasil olan toga secara online. Selain kegiatan cerama, pelatihan secara praktik juga dilakukan oleh ibu PKK Desa Pandanrejo Kecamatan Wagir Kabupaten Malang.

\section{Sasaran Kegiatan}

$\begin{array}{rrrr} & \text { Sasaran } & \text { kegiatan } & \text { pengabdian } \\ \text { adalah } & \text { Ibu } & \text { PKK } & \text { (Pembinaan }\end{array}$ Kesejahteraan Keluarga) di desa Pandenrejo, Kecamatan Wagir, Kabupaten Malang. Adapun target sasaran adalah minimal 30 orang. 
Langkah-langkah Kegiatan pengabdian

Langkah-langkah

dalam

pengabdian ini adalah: pertama, menyebarkan undangan kepada Ibu-ibu PKK yang berisi informasi terkait tema, waktu, dan tempat pelaksanaan kegiatan pengabdian. Kedua, penyampaian materi kegiatan tentang TOGA, khasiat, dan pengolahan TOGA Ketiga, melakukan praktek terkait pengolahan tanaman toga. Keempat penyampaian materi tentang pemasaran online hasil olahan TOGA.

\section{Bahan, Alat dan Cara Pengolahan}

Minuman 1

Bahan :

- 10 ruas Jahe

- 5 batang Sereh

- 3 buah kayu manis

- 2 jeruk nipis

- Gula merah secukupnya

- 2 liter air

Alat :

- Kompor

- Panci

- Pisau

- Gelas

Cara Membuat:

1. Kupas jahe hingga bersih

2. Kemudian cuci jahe dan sereh hingga bersih

3. Lalu geprek jahe dan sereh dengan pisau hingga memar

4. Panaskan air dalam panci, dan masukkan semua bahan- bahan yang sudah disiapkan

5. Tunggu hingga mendidih agar sarisari bahan tersebut dapat keluar dengan sempurna

6. Jika sudah, dapat dipindah kan dalam gelas yang sudah di siapkan.
Minuman 2

Bahan

- $\quad 100 \mathrm{~g}$ jahe $/ 800 \mathrm{ml}$ air

- 2 batang sereh

- $\quad 150 \mathrm{~g}$ gula merah

- 2 buah kayu manis

- 7 biji kapulaga

- 5 lembar daun salam

- Setengah buah jeruk nipis

- 2 liter air

Alat :

- Kompor

- Panci

- Pisau

- Gelas

Cara Membuat:

- Kupas jahe hingga bersih.

- Kemudian cuci jahe, sereh, daun salam dan kapulaga hingga bersih.

- Lalu geprek jahe dan sereh hingga memar.

- Iris gula merah yang telah disiapkan

- Panaskan air dalam panci dan masukkan semua bahan-bahan yang telah disiapkan.

- Tunggu hingga mendidih agar sarisari dari bahan tersebut dapat keluar dengan sempurna.

- Jika sudah dapat dipindahkan ke dalam gelas yang sudah disiapkan.

\section{HASIL DAN PEMBAHASAN}

Kegiatan pengolahan tanaman TOGA menjadi produk minuman sebagai bentuk pemberdayaan ekonomi perempuan di Desa Pandanrejo Kecamatan Wagir Kabupaten Dau terlaksana dengan baik. 
Peserta pelatihan dihadiri oleh $30 \mathrm{ibu}-\mathrm{ibu}$ PKK dari 40 undangan yang disebarkan, hal ini menunjukkan ibu-ibu PKK sangat antusias untuk mengikuti pelatihan ini.

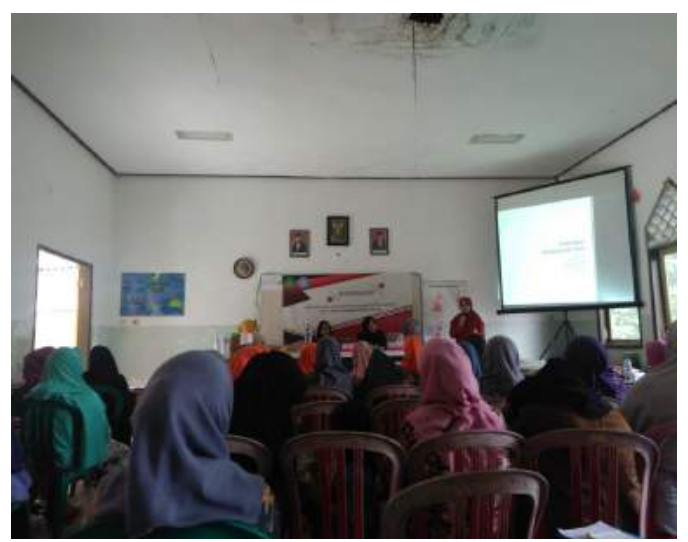

Gambar 1. Pelatihan Pembuatan Minuman dari TOGA

\section{Khasiat Tanaman Toga}

Adapun tanaman toga yang diramu dalam pelatihan ini adalah sebagai berikut: Tabel 1. Khasiat Berbagai Tanaman Toga

\begin{tabular}{|c|c|c|c|}
\hline $\begin{array}{l}\mathrm{N} \\
\mathrm{o}\end{array}$ & $\begin{array}{c}\text { Tanama } \\
n\end{array}$ & Khasiat & Sumber \\
\hline 1 & $\begin{array}{l}\text { Akar } \\
\text { dan } \\
\text { Daun } \\
\text { Sereh }\end{array}$ & $\begin{array}{l}\text { Mengobati } \\
\text { berbagai } \\
\text { penyakit, } \\
\text { yaitu diare, } \\
\text { batuk, obat } \\
\text { sakit kepala, } \\
\text { penghangat } \\
\text { badan, nyeri } \\
\text { lambung, } \\
\text { penurun } \\
\text { panas, dan } \\
\text { pengusir } \\
\text { nyamuk }\end{array}$ & $\begin{array}{l}\text { G et al., } \\
\text { (2013). }\end{array}$ \\
\hline 2 & Jahe & $\begin{array}{l}\text { Mengobati } \\
\text { berbagai } \\
\text { macam } \\
\text { penyakit } \\
\text { seperti Gout, } \\
\text { Migrain, } \\
\text { Arthritis, } \\
\text { Ostheoartritis, } \\
\text { Hipoglikemi, } \\
\text { Rhematoid } \\
\text { penyakit pada } \\
\text { sistem } \\
\text { gastrointestina }\end{array}$ & $\begin{array}{l}\text { Qamariah } \\
\text { et al., } \\
\text { (2019). }\end{array}$ \\
\hline
\end{tabular}

\begin{tabular}{|c|c|c|c|}
\hline & & $\begin{array}{l}1 \\
\text { Kardiovaskula } \\
\text { r dan } \\
\text { hepatoprotekti } \\
\text { f }\end{array}$ & \\
\hline 3 & $\begin{array}{l}\text { Kayu } \\
\text { Manis }\end{array}$ & $\begin{array}{l}\text { Menghilangka } \\
\mathrm{n} \text { sakit } \\
\text { (analgesik), } \\
\text { melancarkan } \\
\text { peredaran } \\
\text { darah, dan } \\
\text { peluruh kentut } \\
\text { (karminatif), } \\
\text { dan } \\
\text { menambah } \\
\text { nafsu makan } \\
\text { (stomakik). }\end{array}$ & $\begin{array}{l}\text { Winarto } \\
(2003)\end{array}$ \\
\hline 4 & $\begin{array}{l}\text { Kapulag } \\
\text { a }\end{array}$ & $\begin{array}{l}\text { Menyembuhk } \\
\text { an rematik, } \\
\text { kejang perut, } \\
\text { sesak nafas, } \\
\text { demam, } \\
\text { menambah } \\
\text { nafsu makan, } \\
\text { menghilangka } \\
\text { n bau badan, } \\
\text { batuk, dan } \\
\text { sebagai obat } \\
\text { radang } \\
\text { amandel. }\end{array}$ & $\begin{array}{l}\text { Winarto } \\
(2003)\end{array}$ \\
\hline 5 & $\begin{array}{l}\text { Cengke } \\
\mathrm{h}\end{array}$ & $\begin{array}{l}\text { Menambah } \\
\text { jumlah darah } \\
\text { putih dan } \\
\text { memperkuat } \\
\text { lendir usus } \\
\text { dan lambung } \\
\text { serta Cengkeh } \\
\text { adalah sumber } \\
\text { vitamin E (alfa } \\
\text { tokoferol), } \\
\text { vitamin K } \\
\text { vitamin C, } \\
\text { kalsium, } \\
\text { magnesium, } \\
\text { zat besi dan } \\
\text { mangan yang } \\
\text { baik. }\end{array}$ & $\begin{array}{l}\text { Kurniawa } \\
\text { ti (2010) }\end{array}$ \\
\hline 6 & $\begin{array}{l}\text { Daun } \\
\text { Salam }\end{array}$ & $\begin{array}{l}\text { Menurunkan } \\
\text { kadar } \\
\text { kolesterol }\end{array}$ & $\begin{array}{l}\text { Harismah } \\
\text { (2017) }\end{array}$ \\
\hline 7 & $\begin{array}{l}\text { Jeruk } \\
\text { Nipis }\end{array}$ & $\begin{array}{l}\text { Penurun } \\
\text { demam, } \\
\text { pereda batuk, }\end{array}$ & $\begin{array}{l}\text { Kurniawa } \\
\text { ti (2010) }\end{array}$ \\
\hline
\end{tabular}




\begin{tabular}{|l|l|l|}
\hline & $\begin{array}{l}\text { antiinflamasi, } \\
\text { dan antiseptik. }\end{array}$ & \\
\hline
\end{tabular}

Tanaman TOGA berdasarkan pada tabel 1 di atas, diolah menjadi menjadi dua produk minuman dengan variasi bahan TOGA yang berberbeda. Perbedaannya hanya pada bahan tanaman Kapulaga dan Daun Salam. Dimana minuman pertama tidak ada bahan-bahan tersebut. Dalam kegiatan ini seluruh peserta pelatihan menyaksikan dan mempraktekkan cara pengolahan TOGA tersebut sesuai yang disampaikan pemateri.

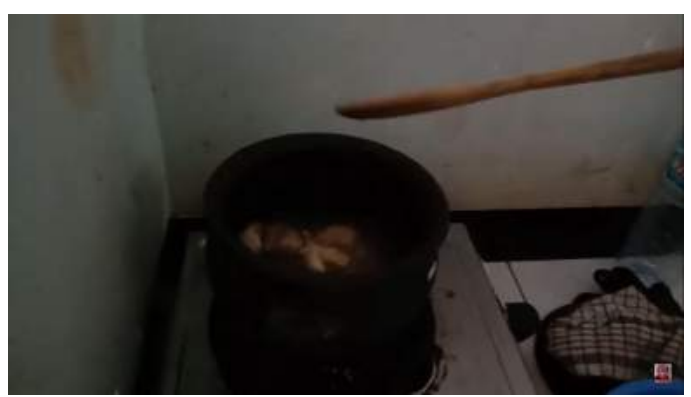

Gambar 2. Proses Pembuatan Minuman TOGA

Kemudian, hasil dari olahan TOGA berupa minuman dapat dinimati oleh peserta dengan membandingkan dua varian minuman yang berbeda. Dari hasil uji tester, peserta pelatihan lebih banyak menyukai yang minuman yang kedua, yaitu minuman yang diberi bahan kapulaga dan daun salam. Mereka mengatakan bahwa minuman yang kedua lebih terasa enak dan segar.

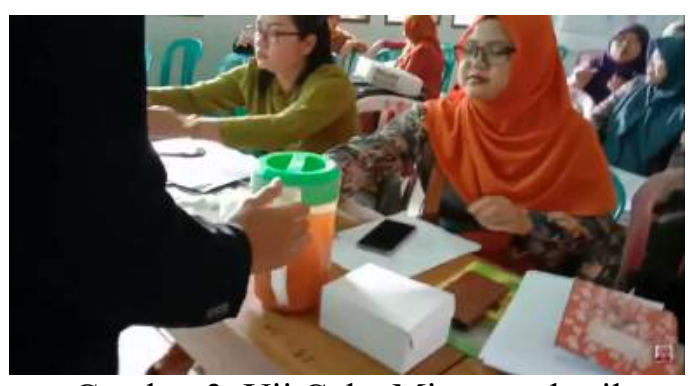

Gambar 3. Uji Coba Minuman hasil pengolahan TOGA
Selanjutnya, peserta mendapatkan pelatihan tentang pemasaran produk secara online. Pelatihan pemasaran online diberikan bertujuan untuk memberikan alternatif solusi dari warga di desa Pandanrejo tentang mudahnya melakukan pemasaran secara online. Karena masih masih banyak masyarakat yang menganggap bahwa memasarkan produk lebih sulit dibandingkan dengan menghasilkan produk. Padahal memasarkan produk secara online merupakan strategi promosi produk dengan biaya murah, yaitu mengandalkan smartphone dan nomor kontak. Oleh karena itu, Masyarakat dapat memanfaatkan sosial media di era modern ini. Karena secara strategis, dengan penjualan online ini dapat mempermudah serta memperluas dari pemasaran produk (Nisa \& Suyanto (2018).

Berdasarkan hasil tanggapan peserta atas pelatihan yang sudah dilaksanakan, sebanyak $85 \%$ peserta dari 30 peserta yang mengikuti pelatihan memberikan tanggapan bahwa sangat memahami atas materi yang diberikan serta cara mempraktikkan materi tersebut. Sedangkan $15 \%$ lainnya kurang memahami karena faktor usia yang sudah tidak lagi di usia produktif sehingga cukup mengalami kesusahan dalam memahami tentang aplikasi digital yang disampaikan dalam kegiatan pelatihan. Berdasarkan tanggapan peserta yang sebagian besar memahami materi pelatihan, maka selanjutnya ketua PKK yang juga sebagai istri dari kepala desa Pandanrejo mencoba untuk mengangkat produk ini menjadi salah satu produk di program Usaha Peningkatan Peningkatan Pendapatan Keluarga Sejahtera (UPPKS). Program ini dapat menjadi kegiatan ekonomi produktif yang dapat meningkatkan pendapatan keluarga yang dapat dilakukan secara berkelompok di lingkungan masyarakat yang sederhana. 


\section{SIMPULAN}

Kegiatan pengolahan tanaman TOGA menjadi produk minuman sebagai bentuk pemberdayaan ekonomi perempuan di Desa Pandanrejo Kecamatan Wagir Kabupaten Dau terlaksana dengan baik dengan respon peserta yang memahami materi pelatihan sebanyak $85 \%$. Terdapat produk 2 minuman hasil olahan TOGA dengan variasi bahan TOGA yang berbeda. Perbedaannya hanya pada bahan tanaman Kapulaga dan Daun Salam. Dimana minuman pertama tidak ada bahan-bahan tersebut. Dari hasil uji tester, peserta pelatihan lebih banyak menyukai minuman yang kedua, yaitu minuman yang diberi bahan kapulaga dan daun salam. Sebanyak 75\%, mereka mengatakan bahwa minuman yang kedua lebih terasa enak dan segar.

\section{DAFTAR PUSTAKA}

G, W., -, E., \& Panggabean, A. (2013). Pemanfaatan Tumbuhan Serai Wangi (Cymbopogon Nardus (L.) Rendle) Sebagai Antioksidan Alami. Jurnal Kimia Mulawarman.

Harismah, K. (2017). Pemanfaatan Daun Salam (Eugenia Polyantha) Sebagai Obat Herbal Dan Rempah Penyedap Makanan. Warta Lpm, 19(2), 110-118.

Karo-Karo, U. (2010). Pemanfaatan Tanaman Obat Keluarga di Kelurahan Tanah 600, Medan. Kesmas: National Public Health Journal.

https://doi.org/10.21109/kesmas.v4i5 .169.

Kurniawati, N., \& Qanita, T. R. (2010). Sehat \& cantik alami berkat: Khasiat bumbu dapur. qanita.

Nisa, K., Laili, A., Qolbiyatul, S., \& Suyanto, M. (2018). Strategi Pemasaran Online dan Offline. Jurnal Abdikarya: Jurnal Karya Pengabdian Dosen dan Mahasiswa, 1(1).

Nurdiwaty, D., Puspita, E., Kusumaningtyas, D., Winarko, S. P., Tohari, A., Solikah, M. A., \& Faisol, F. (2017). Pemberdayaan Wanita Melalui Tanaman Toga Untuk Membantu Meningkatkan Pendapatan Keluarga. Jurnal ABDINUS: Jurnal Pengabdian Nusantara, 1(1), 20-27.

Nurjanah, S. R., Nurazizah, N. N., Septiana, F., \& Shalikhah, N. D. (2019). Peningkatan Kesehatan Masyarakat Melalui Pemberdayaan Wanita dalam Pemanfaatan Pekarangan dengan Tanaman Obat Keluarga (TOGA) di Dusun Semawung. Community Empowerment.

https://doi.org/10.31603/ce.v4i1.300 3

Nursyamsu, R. (2018). Pelatihan Peningkatan Kapasitas Pemuda Dan Pembuatan Program Kerja Pada Organisasi Pemuda Desa Cibinuang, Kabupaten Kuningan. Empowerment: Jurnal Pengabdian Masyarakat.

https://doi.org/10.25134/empowerme nt.v1i02.1572

Qamariah, N., Handayani, R., \& Novaryatiin, S. (2019). Peningkatan Pengetahuan dan Keterampilan Ibu Rumah Tangga dalam Pengolahan Tanaman Obat Keluarga (TOGA) sebagai Ramuan Obat Tradisional. PengabdianMu: Jurnal Ilmiah Pengabdian Kepada Masyarakat. https://doi.org/10.33084/pengabdian 
mu.v4il.692.

Solikah, M. A., \& Faisol, F. (2017). Pemberdayaan Wanita Melalui Tanaman Toga Untuk Membantu Meningkatkan Pendapatan Keluarga. Jurnal ABDINUS: Jurnal Pengabdian Nusantara, 1(1), 20-27.
Winarto, I. W., \& Karyasari, T. (2003). Memanfaatkan bumbu dapur untuk mengatasi aneka penyakit. AgroMedia. 